\title{
ANALYSIS OF A BUSINESS FEASIBILITY STUDY USING A BUSINESS MODEL CANVAS FOR THE ESTABLISHMENT OF A SUBSIDIARY IN THE TRAINING PROVIDER FIELD
}

\author{
Ahmad Mukhibbin ${ }^{1)}$, Marni Astuti' ${ }^{2)}$, Eko Poerwanto ${ }^{3)}$ \\ Program Studi Teknik Industri Sekolah Tinggi Teknologi Adisutjipto Yogyakarta \\ Jl. Janti Blok-R Lanud Adisutjipto Yogyakarta \\ Email : ${ }^{1}$ ahmadmukhibbin501@gmail.com
}

\begin{abstract}
PT. XYZ is a company engaged in aircraft MRO (Maintenance, Repair and Repair) services by providing integrated solutions for all of its customers. Unit Learning Services at PT. XYZ has the task of organizing education and training. In accordance with the plan of PT. XYZ, Learning Services Unit is focused on preparing to spin off to become a subsidiary engaged in the Provider of Training. This study aims to determine what kind of subsidiary business model will be created using the canvas business model and conduct a business feasibility study, whether it is feasible or not. The results of this study are based on the canvas business model which has the following proposition values: (1) Highly qualified instructors with years of experience in aircraft maintenance; (2) Aircraft access for training; (3) Spacious classrooms including ACT instructors for Airbus qualified training classes; (4) Adjustable training for customer needs; and based on aspects that are processed for the establishment of a subsidiary is declared feasible.
\end{abstract}

Keywords: Training Provider, Business Model Canvas, Business Feasibility Study

\section{Pendahuluan}

Secara harfiah, anak perusahaan adalah perusahaan yang dikuasai oleh pihak lain, baik secara langsung maupun tidak langsung melalui satu atau lebih badan lainnya. Dilihat dari kepemilikan saham, anak perusahaan atau subsidiary corporation merupakan perusahaan dimana mayoritas sahamnya, umumnya lebih dari 50\% dimiliki oleh induk perusahaan. Dengan jumlah saham ini induk perusahaan berhak mengendalikan operasi dan manajemen anak perusahaan. (Sumber : Presisi April 2019; hlm.24\&25).

Pembentukan anak usaha dapat dilakukan dengan beberapa prosedur antara lain prosedur residu, prosedur penuh dan terprogram. Anak perusahaan yang terbentuk dari prosedur residu berasal dari pemecahan induk perusahaan sesuai sektor usaha. Prosedur penuh cocok dilakukan bagi perusahaan yang belum pernah terjadi pemecahan sebelumnya. Sedangkan untuk terprogram biasanya strategi bisnis yang dimulai dengan pembentukan holding company yang dilanjutkan dengan pembentukan anak perusahaan melalui akusisi, joint venture dan lain-lain. (Sumber : Presisi April 2019;hlm.25).

Pembentukan grup perusahaan tentuya berdampak positif bagi anggotanya. Keuntungan pertama adanya kemandirian risiko bagi induk maupun anak perusahaan. Keuntungan berikutnya adalah kontrol yang lebih mudah dan efektif bagi induk perusahaan. Anak perusahaan pun bisa saling bekerja sama dan berkoordinasi dalam operasionalnya sehari-hari sehingga tercipta efisiensi operasional perusahaan dan memastikan anak perusahaan tidak overlapping. Dengan melihat berbagai keuntungan 
ini, PT. XYZ dalam mengembangkan usahanya sudah tepat. Pada tahun 2019, PT. XYZ akan membentuk 6-7 anak perusahaan dengan harapan bisnis PT. XYZ semakin berkembang dan mampu mencapai visinya. (Sumber : Presisi April 2019;hlm.25)

PT. XYZ merupakan perusahaan yang bergerak di bidang jasa MRO (Maintenance, Repair, and Overhaul) pesawat terbang. PT. XYZ saat ini merupakan perusahaan jasa MRO terbaik di Indonesia dengan menyediakan solusi terintegrasi bagi seluruh customernya. Tak hanya itu PT. XYZ saat ini juga sudah memiliki klien dari 60 negara yang tersebar di 6 benua. Pada perusahaan PT. XYZ terdapat Unit Learning Services yang memiliki tugas menyelenggarakan pendidikan dan pelatihan. Sesuai dengan rencana PT. XYZ pada saat ini Unit Learning Services tersebut fokus pada persiapan melakukan pelepasan (spin off) untuk menjadi anak perusahaan yang bergerak dibidang Training Provider.

Berdasarkan latar belakang di atas, maka perumusan masalah dalam penelitian ini adalah :

a. Bagaimana model bisnisnya berdasarkan business model canvas?

b. Dan Apakah pendirian anak perusahaan PT. XYZ di bidang training provider layak atau tidak untuk dijalankan?

\section{Metodologi Penelitian}

Penelitian ini termasuk jenis penelitian kualitatif analisis dan kuantitatif. Dimana pengolahan data pada penelitian ini dilakukan secara kualitatif dan kuantitatif. Dalam melakukan penelitian ini, gambar 1 berikut merupakan gambaran metodologi penelitian yang dilakukan.

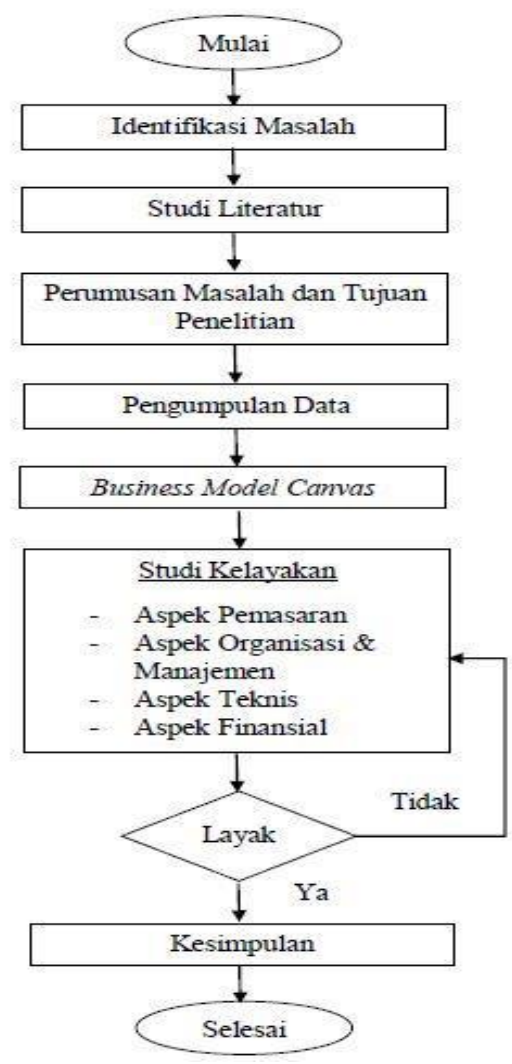

Gambar 1 Diagram Alir Penelitian 
Agar dapat memberikan gambaran dari permasalahan yang akan dipecahkan untuk mencapai tujuan penelitian secara umum, maka penjelasan dari diagram alir di atas adalah sebagai berikut :

a. Identifikasi Masalah

Melakukan observasi di Unit Learning Services PT. XYZ untuk mengidentifikasi masalah sebagai bahan penelitian.

b. Studi Literartur

Melakukan kajian pustaka, yaitu mempelajari buku-buku referensi dan hasil penelitian sejenis sebelumnya yang pernah dilakukan oleh orang lain.

c. Perumusan Masalah dan Tujuan Penelitian

Melakukan perumusan masalah agar permasalahan bisa terfokuskan dan menentukan tujuan yang didapatkan dalam penelitian.

d. Pengumpulan Data

Mengumpulkan data-data yang dibutuhkan, kemudian diolah sebagai bahan untuk dianalisa.

e. Business Model Canvas

Menentukan gambaran bisnis model dengan mengisi komponen-komponen business model canvas.

f. Studi Kelayakan

Melakukan pengolahan data dan pembahasan untuk dapat memperoleh solusi, dengan menggunakan aspek pemasaran, aspek organisasi \& manajemen, aspek teknis, dan aspek finansial.

g. Layak/Tidak

Memustuskan hasil pengolahan data dan pembahasan dinyatakan layak atau tidak.

h. Kesimpulan

Pernyataan singkat dan jelas tentang hasil penelitian yang diperoleh, serta memuat usulan atau pendapat yang diberikan peneliti.

Pada penelitian ini peneliti mengumpulkan data dari objek penelitian dengan menggunakan jenis data primer. Data primer dapat didefinisikan sebagai data yang dikumpulkan dari sumber-sumber asli untuk tujuan tertentu (Kuncoro, 2009: Prabowo, 2014). Pengumpulan data primer pada penelitian ini dilakukan dengan cara sebagai berikut :

a. Wawancara, dilakukan dengan menyampaikan pertanyaan secara lisan kepada mentor, karyawan, dan instuktur mengenai hal-hal yang berkaitan dengan proses pendirian anak perusahaan.

b. Observasi, data-data yang diperoleh dengan melakukan pengamatan dan pencatatan untuk menyakinkan serta melengkapi data-data yang sebelumnya telah ada.

Selain menggunakan data primer, penelitian ini juga menggunakan data sekunder yaitu dengan mencari data dari website perusahaan, dan websitewebsite lainnya yang dapat mendukung data primer.

\section{Hasil dan Pembahasan}

\subsection{Business Model Canvas}

Berdasarkan pengumpulan data di atas, maka bisnis model anak perusahaan di bidang training provider yang akan didirikan dapat digambarkan dengan business model canvas sebagai berikut : 


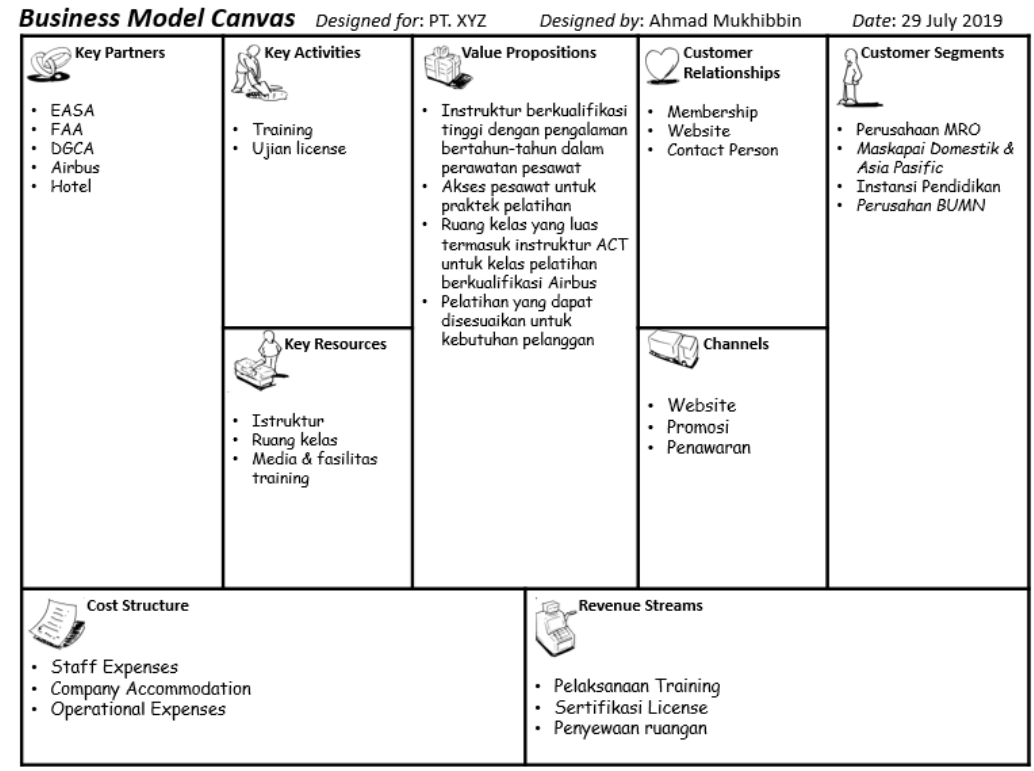

Gambar 2. Tampilan Business Model Canvas

\section{Customer Segments}

Dari segmen konsumen yang terdapat dalam Business Model Canvas di atas, terdapat empat segmen konsumen, yaitu :

a. Perusahaan MRO yaitu PT. XYZ, BAT, MMF, dan IAS.

Untuk PT. XYZ semua kebutuhan training pastinya akan dipenuhi oleh anak perusahaan di bidang training provider ini, karena PT. XYZ merupakan induk perusahaan dari anak perusahaan ini. Sedangkan untuk kebutuhan training akan dipenuhi oleh anak perusahan di bidang training provider ini, karena pada tanggal 12 november tahun 2016 PT. XYZ dan MMF sudah menjalin kerjasama untuk melakukan joint operation untuk mendapatkan pangsa pasar perawatan pesawat yang lebih besar. Begitu pula dengan kebutuhan training IAS nantinya juga akan dipenuhi oleh anak perusahaan di bidang training provider ini, karena pada tanggal 9 januari 2019 sudah menjalin kerjasama strategis perawatan pesawat terbang dan industrial services, pemanfaatan bersama fasilitas, termasuk untuk penyediaan fasilitas baru serta pertukaran ketrampilan dan kemampuan antara kedua perusahaan.

b. Maskapai domestik dan asia pasific. Maskapai domestik teridiri dari dua belas maskapai AOC 121 dan tiga maskapai AOC 135. Dari keduabelas maskapai AOC 121 yang bisa diserap untuk melakukan training di anak perusahaan yang bergerak di bidang training provider ini antara lain adalah Garuda Indonesia, Citilink, Sriwijaya Air, dan NAM Air. Garuda Indonesia dan Cilitink tentunya akan memenuhi kebutuhan training personilnya dengan melakukan training di anak perusahaan di bidang training provider ini, karena kedua maskapai ini merupakan satu grup perusahan dengan anak perusahaan di bidang training provider ini.

c. Instansi Pendidikan yaitu perguruan tinggi urusan amto yang ada di indonesia. Perguruan tinggi jurusan amto sendiri di Indonesia berjumlah 10 instansi, tetapi yang menjalin kerjasama khusus dengan PT. XYZ sejumlah 6 perguruan tinggi, antara lain STTA (AP \& EA), Politeknik 
Medan (AP), Unsurya (AP \& EA), Politeknik Sriwijaya (AP \& EA), Politeknik Batam (PPU), Politeknik Malang (AP). Skema kerja sama antara PT. XYZ dengan enam lembaga pendidikan itu berlangsung dengan cara PT. XYZ memberikan tempat magang dan pelatihan lapangan kepada para siswa lembaga pendidikan tersebut.

d. Perusahaan BUMN yaitu yang bergerak di sektor transportasi dan jasa. Dari sektor transportasi dan jasa tersebut terdapat duapuluh tiga perusahaan BUMN. Beberapa perusahaan bumn 58 dari sektor transportasi yang dapat diserap antara lain : PT Angkasa Pura I (Persero), PT Angkasa Pura II (Persero), PT Garuda Indonesia (Persero) Tbk, PT Jasa Marga (Persero) Tbk, PT Kereta Api Indonesia (Persero), PT Merpati Nusantara Airlines (Persero), PT Pelabuhan Indonesia I, II, III, dan IV. Sedangkan dari perusahaan yang lainnya belum bisa langsung diserap.

\section{Value Proposition}

Untuk menjawab kebutuhan dari customer segment, segi capabilities perusahaan sudah bisa terpenuhi. Dengan demikian perusahaan menawarkan value proposition sebagai berikut :

a. Instruktur berkualifikasi tinggi dengan pengalaman bertahuntahun dalam perawatan pesawat. Yang dimaksud dengan berkualifikasi tinggi adalah orang yang sudah memenuhi elemen-elemen kompetensi yang harus dimiliki oleh seorang instruktur dan telah memiliki kemampuan yang mumpuni. Instruktur dibedakan menjadi dua, instructor dan senior.

b. Akses pesawat untuk pelatihan. Dengan didirikannya anak perusahaan di bidang training provider ini berasal dari induk perusahaan yang bergerak di bidang MRO pesawat udara, tentunya fasilitas pesawat udara sudah pasti ada di lini produksinya. Sehingga untuk para peserta training bisa langsung berhadapan langsung dengan objek perawatan 59 pesawat udara. Di perusahaan induknya terdapat dua jenis pesawat komersil, yaitu Wide Body (berkapasitas di atas 200 penumpang) dan Narrow Body (berkapasitas maksimal 200 penumpang).

c. Ruang kelas yang luas termasuk instuktur ACT untuk kelas pelatihan berkualifikasi Airbus. Hal itu ditandai pada hari selasa, 3 juli 2018 PT. XYZ menandatangani perjanjian dengan Airbus. Kerjasama yang dilakukan tersebut adalah untuk Airbus Training Center selama 5 tahun. Kerjasama terkait Airbus Training Center ini menjadikan PT. XYZ sebagai pusat pelatihan perawatan pesawat milik Airbus untuk tipe Airbus A320 CEO dan A320 NEO serta A330. PT. XYZ dan Airbus juga sepakat untuk menambahkan cakupan pelatihan untuk Engine Ground Run Up Aribus A320 dan A330 serta Extended-range Twin-engine Operational Performance Standards (ETOPS) Training.

d. Pelatihan yang dapat disesuaikan untuk kebutuhan pelanggan atau bisa disebut fleksibel. Misalnya untuk kebutuhan training dari 47 outstations PT. XYZ dan Customer yang dari Luar Negeri. Secara tidak langsung anak perusahaan di bidang training provider ini tentunya mengirimkan instruktur ke outstation. 


\section{Channels}

Fungsi dari channels ada tiga, antara lain :

a. Saluran komunikasi yaitu untuk mengkomunikasikan produk yang akan dijual dalam bentuk produk atau jasa. Cara yang akan dilaksanakan untuk memenuhi fungsi komunikasi ini adalah melalui website. Dalam website tersebut nantinya akan memuat gambaran singkat dan informasiinformasi penting dari anak perusahaan di bidang provider ini.

b. Saluran pemasaran yaitu untuk memasarkan jasa yang akan dijual oleh anak perusahaan di bidang training provider ini. Cara yang akan dilaksanakan untuk melakukan saluran pemasaran yaitu dengan promosi di brosur yang di cantumkan di website maupun di print out dan melakukan penawaran menggunakan proposal bisa dikirim via email atau dalam bentuk fisik.

c. Saluran distribusi yaitu untuk menyalurkan jasa training dari perusahaan ke customer. Cara yang dilakukan ada dua yaitu dengan melakukan training di perusahaan atau di hotel untuk mendukung training yang di luar daerah ataupun luar negeri.

4. Customer Relationships

Fungsi dari Customer Relationship yaitu :

a. Customer aquistion atau menarik pelanggan yaitu dengan memanfaatkan website yang berisikan artikel yang berkaitan dengan training dan melakukan kerjasama strategis dengan calon pelanggan;

b. Customer retention atau mempertahankan pelanggan yaitu dengan membuat membership dan memberikan kuisioner kepada peserta training untuk memberikan penilaian selama pelaksanaan training sebagai bahan evaluasi bagi perusahaan untuk memperbaiki atau menambah kekurangan training yang disajikan agar training kedepannya tidak ada kekurangan lagi dan menjadi lebih baik dari training sebelumnya.

c. Boosting sales atau meningkatkan penjualan yaitu dengan memanfaatkan contact person whatsapp atau line untuk pelanggan agar menjadi pelanggan yang loyal.

5. Revenue Streams

Sumber arus pendapatan bagi perusahaan training provider ini berasal dari tiga sumber yaitu :

a. Pelaksanaan training. baik training yang dilaksanakan di perusahaan maupun yang dilaksanakan di outstation luar daerah dan luar negeri.

b. Sertifikasi lisence yaitu dengan melaksanakan examination untuk memperoleh sertifikat atau lisence berkaitan dengan kompetensi training tertentu.

c. Penyewaan ruangan atau alat yaitu dengan menyewakan ruang kelas ataupun ruang meeting untuk kepentingan di luar dari operasional training.

6. Key Resources

Sumber daya utama yang harus dimiliki perusahaan training provider ini adalah

a. Instruktur; Tentunya instruktur yang dimiliki telah terbukti dan teruji atas pengetahuan dan kemampuan dalam melakukan perawatan pesawat udara. 
b. Ruang kelas yang terdiri dari 30 ruang beserta isinya dan ruang meeting yang berjumlah 5 ruang meeting beserta isinya.

c. Media dan fasilitas training diantaranya pesawat, komputer, sofeware, dll.

\section{Key Activities}

Aktivitas kunci pada perusahaan training provider ini adalah dengan melaksanaka training dan examination untuk memperoleh sertifikat ataupun lisence berkaitan dengan kompetensi training tertentu.

8. Key Patnerships

Mitra-mitra utama yang harus dimiliki perusahaan training provider ini di dalam menjalankan bisnisnya yaitu EASA, DGCA, Airbus, dan hotel. EASA, FAA, DGCA, Airbus dibutuhkan approval training, kurikulum/syllabus yang akan diajarkan pada saat pelaksanaan training dan hotel dibutuhkan untuk melaksanakan training yang diselenggarakan di luar daerah maupun di luar negeri.

9. Cost Structure

Struktur biaya yang harus dikeluarkan untuk perusahaan training provider ini yaitu : Staff Expenses (Gaji SDM, dll); Company Accommodation (akomodasi instruktur seperti makan, transportasi, penyewaan hotel, dll jika training di luar daerah); Operational Expenses (seperti tagihan listrik, air, internet, dll).

\subsection{Aspek Pemasaran}

Berdasarkan customer segments pada business model canvas di atas, yang terdiri dari perusahaan MRO, maskapai domestik \& asia pasific, instansi pendidikan (perguruan tinggi jurusan AMTO), perusahaan bumn (transportasi \& pergudangan).

Dari empat perusahaan MRO yang ada yaitu tiga diantaranya dapat diserap oleh perusahaan training provider ini dengan kata lain sebesar $75 \%$ dari training perusahaan MRO. Maskapai domestik yang terdiri dari 12 maskapai AOC 121 dan 3 maskapai AOC 135 dapat diserap yang pasti ada garuda indonesia, citilink, sriwijaya air, dan nam air. Namun untuk maskapai yang lain bukan tidak mungkin untuk bisa diserap oleh perusahaan training provider ini dengan kata lain sebesar $30 \%$ dari maskapai domestik. Untuk maskapai asia pasific hanya sebagian kecil yang bisa diserap. Instansi pendidikan yang pasti diserap sebanyak 6 dari 10 perguruan tinggi jurusan AMTO, dengan kata lain sebesar $60 \%$. Yang 4 perguruan tinggi lainnya bisa saja diserap walaupun tidak melakukan kerjasama khusus yang dilakukan 6 perguruan tinggi antara lain antara lain STTA (AP \& EA), Politeknik Medan (AP), Unsurya (AP \& EA), Politeknik Sriwijaya (AP \& EA), Politeknik Batam (PPU), Politeknik Malang (AP).

\subsection{Aspek Organisasi dan Manajemen}

\section{a. Organisasi}

Dengan sumber daya manusia yang dimiliki unit learning services saat ini yaitu 59 orang, nantinya semua sumber daya manusia ini akan dipindah tugaskan ke perusahaan training provider yang baru. Maka dari itu perusahaan training provider ini tidak akan merekut SDM lagi untuk pendirian anak 
perusahaan ini. Hanya saja dari 59 orang sumber daya manusia yang tersedia ini ditempatkan dengan skema organisasi dan manajemen yang baru. (Sumber : Data dari Mentor).

b. Manajemen

Pada tahapan studi kelayakan, pelaksana yang melakukan studi adalah SDM unit learning services itu sendiri yang sudah diberikan tugas oleh PT. XYZ untuk mempersiapkan proses pelepasan (spin off) dari PT. XYZ), tentunya dengan melaksanakan meeting untuk membahas tentang progres dari studi kelayakan itu sendiri. Jadwal penyelesaian pendirian anak perusahaan ini ditargetkan pada kuartal ke-4 / akhir tahun 2019 sudah selesai. Tentunya target ini bisa tercapai karena dalam persiapan pendirian anak perusahaan ini tidak melakukan pembangunan, melainkan dengan cara/metode inbreng yaitu melakukan penyerahan aset dari PT. XYZ ke anak perusahaan yang nantinya akan didirikan.

\subsection{Aspek Teknis}

a. Bentuk Badan Usaha

Anak perusahaan inin nantinya akan berbentuk Perseroan Terbatas (PT) yang menjalankan usahanya dengan memilii modal yang terdiri dari sahamsaham dan pemiliknya mempunyai bagian sebanyak saham yang dimilikinya. Saham dari anak perusahaan ini pastinya mayoritas dimiliki oleh induk perusahaan yaitu PT. XYZ.

b. Penetuan Lokasi

Lokasi anak perusahaan ini berada di satu tempat dengan perusahaan induk yaitu di kota tangerang kawasan bandara soekarno-hatta. Alasan anak perusahaan ini berada di sana adalah dekat dengan para konsumen dan stackholder yang berhubungan dengan keberlangsungan opersional perusahaan. c. Jenis Usaha

Jenis usaha anak perusahaan ini berupa training provider yaitu penyedia jasa training di bidang MRO training. tentunya produksi dari anak 67 perusahaan ini berupa pelaksanaan training maupun examination certificate atau lisence.

d. Sarana dan Prasarana

Sarana yang digunakan antara lain : ruang kelas sebanyak 30 ruang, ruang meeting sebanyak 5 ruang, dan 1 office. Prasarana yang dibutuhkan adalah akses jalan, listrik, dan air. Dari penentuan lokasi di atas untuk kebutuhan yang digunakan oleh sarana dan prasarana sudah terpenuhi.

e. Mesin dan Alat Yang Digunakan

Mesin-mesin yang digunakan untuk kebutuhan training misalnya pesawat udara, komponen pesawat udara, dll. Alat yang digunakan adalah benda untuk menunjang kegiatan training misalnya komputer, sofeware, dll. 


\subsection{Aspek Finansial}

\section{a. Total Investasi}

Tabel 1. Total Investasi

\begin{tabular}{|c|c|c|}
\hline \multicolumn{2}{|l|}{ Sofeware } & $\$ \quad 71.428,57$ \\
\hline E-Learning & $\$ 15 \cdot 190,37$ & \\
\hline Self Development Aplication (SDA) & $\$ 11.038,20$ & \\
\hline IT-MRO (SWIFT) & $\$ 45.200,00$ & \\
\hline \multicolumn{2}{|l|}{ Building } & $\$ \quad 464.285,71$ \\
\hline 30 Ruang Kelas & $\$ 257.142,86$ & \\
\hline 5 Ruang Meeting & $\$ 142.856,14$ & \\
\hline 1 Office & $\$ 64.286,71$ & \\
\hline \multicolumn{2}{|l|}{ Furniture } & $35.714,28$ \\
\hline 750 Meja & $\$ 21.428,57$ & \\
\hline 750 Kursi & $\$ 14.285,71$ & \\
\hline \multicolumn{2}{|l|}{ Tools \& Equipments } & $\$ \quad 500.000,00$ \\
\hline 125 Komputer & $\$ 142.857,14$ & \\
\hline Komponen-Komponen Pesawat & $\$ 357.142,86$ & \\
\hline \multicolumn{2}{|l|}{ Working Capital } & $\$ \quad 357.142,86$ \\
\hline Persiapan Pendirian Perusahaan & \$ $71.428,57$ & \\
\hline Kebutuhan Perusahaan Jangka Pendek & $\$ 285.714,29$ & \\
\hline \multicolumn{2}{|l|}{ Total } & $\$ 1.428 .571,42$ \\
\hline
\end{tabular}

\section{b. Total Biaya}

Tabel 2. Total Biaya

\begin{tabular}{|c|c|c|}
\hline \multicolumn{2}{|c|}{ Staff Expenses } & \$ $2.025 .843,64$ \\
\hline 17 Instructor & $\begin{array}{ll}\text { S } & 123.857,14\end{array}$ & \\
\hline 10 Senior Instructor & $85.714,29$ & \\
\hline SDM lainnya & $\$ 1.816 .272,21$ & \\
\hline \multicolumn{2}{|c|}{ Company Accommodation } & $\begin{array}{ll} & 180.839,87\end{array}$ \\
\hline 17 Instructor & $\$ \quad 109.211,30$ & \\
\hline 10 Senior Instructor & $\$ \quad 71.628,57$ & \\
\hline \multicolumn{2}{|c|}{ Operational Expenses } & $\begin{array}{l}\mathbf{2 1 6 . 4 7 3 , 0 6} \\
\end{array}$ \\
\hline Biaya Listrik & $\$ \quad 42.857,14$ & \\
\hline Biaya Air & $\begin{array}{ll} & 17.857,14 \\
\end{array}$ & \\
\hline Biaya Internet & $\begin{array}{ll}\text { \$ } & 10.714,29 \\
\end{array}$ & \\
\hline Biaya Operasional Training & $\begin{array}{ll}\$ & 145.044,49 \\
\end{array}$ & \\
\hline \multicolumn{2}{|l|}{ Total } & S 2.423.156,57 \\
\hline
\end{tabular}

\section{c. Total Pendapatan}

Tabel 3. Total Pendapatan

\begin{tabular}{|c|c|c|c|}
\hline \multicolumn{3}{|c|}{ Perusahaan MRO } & $\$ 13.749 .821,43$ \\
\hline $\mathrm{XYZ}$ & & $13.571 .428,57$ & \\
\hline MMF & & $6.428 .571,43$ & \\
\hline IAS & $\$$ & $92.142,86$ & \\
\hline \multicolumn{3}{|c|}{ Maskapai Domestik } & S $3.285 .000,00$ \\
\hline Garuda Indonesia & $\$$ & $2.678 .571,43$ & \\
\hline Citilink & $\$$ & $429.642,86$ & \\
\hline Sriwijaya Air & $\$$ & $136.607,14$ & \\
\hline NAM Air & $\$$ & $40.178,57$ & \\
\hline \multicolumn{3}{|c|}{ Instansi Pendidikan } & $308.571,43$ \\
\hline STTA (AP \& EA) & $\$$ & $68.571,43$ & \\
\hline Politelnnik Medan (AP) & $\$$ & $34.285,71$ & \\
\hline Unsurya (AP \& EA) & $\$$ & $68.571,43$ & \\
\hline Politeknik Sriwijaya (AP \& EA) & $\$$ & $68.571,43$ & \\
\hline Politelnik Batam (PPU) & $\$$ & $34.285,71$ & \\
\hline Politelnnik Malang (AP) & $\$$ & $34.285,71$ & \\
\hline \multicolumn{3}{|l|}{ Total } & $\$ 17.343 .392,86$ \\
\hline
\end{tabular}


d. Laba Rugi Sebelum Pajak dan Sesudah Pajak

Tabel 4. Laba Rugi Sebelum Pajak

\begin{tabular}{|c|c|c|c|c|c|}
\hline Tahun & Total Pendapatan & Total Biaya & EBT & $\begin{array}{c}\text { Tax 2\% } \\
\text { (dari bruto) }\end{array}$ & EAT \\
\hline 2020 & $\$ 17.343 .392,86$ & $\$ 2.423 .156,57$ & $\$ 14.920 .236,29$ & $\$ 346.867,86$ & $\$ 14.573 .368,43$ \\
\hline 2021 & $\$ 17.343 .392,86$ & $\$ 2.423 .156,57$ & $\$ 14.920 .236,29$ & $\$ 346.867,86$ & $\$ 14.573 .368,43$ \\
\hline 2022 & $\$ 17.343 .392,86$ & $\$ 2.423 .156,57$ & $\$ 14.920 .236,29$ & $\$ 346.867,86$ & $\$ 14.573 .368,43$ \\
\hline 2023 & $\$ 17.343 .392,86$ & $\$ 2.423 .156,57$ & $\$ 14.920 .236,29$ & $\$ 346.867,86$ & $\$ 14.573 .368,43$ \\
\hline 2024 & $\$ 17.343 .392,86$ & $\$ 2.423 .156,57$ & $\$ 14.920 .236,29$ & $\$ 346.867,86$ & $\$ 14.573 .368,43$ \\
\hline \multicolumn{5}{|c|}{ Total } & $\$ 72.866 .842,16$ \\
\hline
\end{tabular}

e. Aliran Kas Bersih

Tabel 5. Aliran Kas

\begin{tabular}{|c|c|}
\hline Tahun & EAT $=$ AKB \\
\hline 2020 & $\$ 14.573 .368,43$ \\
\hline 2021 & $\$ 14.573 .368,43$ \\
\hline 2022 & $\$ 14.573 .368,43$ \\
\hline 2023 & $\$ 14.573 .368,43$ \\
\hline 2024 & $\$ 14.573 .368,43$ \\
\hline Total & $\$ 72.866 .842,16$ \\
\hline
\end{tabular}

\section{f. Total PV Aliran Kas Bersih}

Tabel 6. Total PV Aliran Kas

\begin{tabular}{|c|c|c|c|}
\hline Tahun & Aliran Kas Bersih & $\begin{array}{c}\text { Discount Factor } \\
20 \%\end{array}$ & PV AKB \\
\hline 2020 & $\$ 14.573 .368,43$ & 0,833 & $\$ 12.139 .615,90$ \\
\hline 2021 & $\$ 14.573 .368,43$ & 0,694 & $\$ 10.172 .211,16$ \\
\hline 2022 & $\$ 14.573 .368,43$ & 0,579 & $\$ 8.437 .980,32$ \\
\hline 2023 & $\$ 14.573 .368,43$ & 0,482 & $\$ 7.024 .363,58$ \\
\hline 2024 & $\$ 14.573 .368,43$ & 0,402 & $\$ 5.858 .494,11$ \\
\hline \multicolumn{3}{|c|}{ Total PV Aliran Kas Bersih } & $\$ 43.632 .665,08$ \\
\hline
\end{tabular}

\section{g. Perhitungan Alat Investasi}

- Payback Period = (Investasi Awal / Aliran Kas Bersih) $X 1$ Tahun

$=(\$ 1.428 .571,42 / \$ 14.573 .368,43) \times 1$ Tahun

$=0,098$ Tahun $=>1,2$ Bulan

Dengan demikian berdasarkan perhitungan Payback Period, maka dinyatakan layak. Karena hasil Payback Periodnya 1,2 bulan $<5$ tahun.

- Net Present Value = Total PV Aliran Kas Bersih - Total PV Investasi

$$
\begin{aligned}
& =\$ 43.632 .665,08-\$ 1.428 .571,42 \\
& =\$ 42.204 .093,66
\end{aligned}
$$

Dengan demikian berdasarkan perhitungan Net Present Value, maka dinyatakan layak. Karena hasil Net Present Valuenya \$ 42.204.093,66 >0 


\section{- Profitability Index $=$ Total PV Aliran Kas Bersih / Total Investasi$$
=\$ 43.632 .665,08 / \$ 1.428 .571,42
$$$$
=30,54286574
$$

Dengan demikian berdasarkan perhitungan Profitabilty Index, maka dinyatakan layak. Karena hasil Profitabilty Indexnya 30,54286574 > 1.

$$
\begin{aligned}
& =\frac{\text { Total Pendapatan-Total Investasi }}{\text { Total Investasi }} \times 100 \% \\
& =\frac{\$ 17.343 .392,86-\$ 1.428 .571,42}{\$ 1.428 .571,42} \times 100 \%
\end{aligned}
$$$$
=1.114,037507 \%
$$

Dengan demikian berdasarkan perhitungan Return Of Invesment, maka dinyatakan layak. Karena hasil Return Of Invesment 1.114,037507\%.

\section{Kesimpulan}

1. Berdasarkan business model canvas, gambaran model bisnis yang tepat untuk pendirian anak perusahaan ini adalah sebagai berikut :

a. Customer Segment

Custumer segment terdiri dari Perusahaan MRO, maskapai domestik dan asia pasific, Instansi Pendidikan (perguruan tinggi jurusan amto) dan perusahaan BUMN sektor transportasi.

b. Value Proposition

Value proposition berupa instruktur berkualifikasi tinggi dengan pengalaman bertahun-tahun dalam perawatan pesawat, askes pesawat untuk praktek pelatihan, ruang kelas yang luas termasuk instruktur ACT untuk kelas pelatihan berkualifikasi airbus, dan pelatihan yang dapat disesuaikan untuk kebutuhan pelanggan.

c. Channels

Channels terdiri dari website, promosi, dan penawaran.

d. Customer Relationship

Customer relationship berupa membership, website, dan contact person (WA atau Line)

e. Revenue Streams

Revenue streams diperoleh dari pelaksanaan training, sertifikasi lisence, dan penyewaan ruangan.

f. Key Resources

Key resources yang harus dimiliki adalah instruktur, ruang kelas, media \& fasilitas training.

g. Key Activities

Key activities yang dilakukan adalah training dan ujian lisence

h. Key Patnership

Key patnership yang harus diajak kerjasama untuk berlangsungnya bisnis adalah EASA, FAA, DGCA, Airbus, dan Hotel.

i. Cost Structure

Cost structure yang harus dibayar untuk kegiatan bisnis ini terdiri dari staff expenses, company accommodation, dan operation expenses. 
2. Berdasarkan aspek pemasaran pendirian anak perusahaan training provider ini layak dilaksanakan. Dilihat dari pangsa pasar yang menjanjikan dan memiliki prospek baik kedepannya.

3. Berdasarkan aspek organisasi dan manajemen pendirian anak perusahaan ini layak dilaksanakan. Dilihat dari sumber daya manusia yang berkompeten di bidangnya dan pengelolaan manajemen perusahaan yang jelas.

4. Berdasarkan aspek teknis pendirian anak perusahaan di bidang training provider ini layak dilaksanakan. Dilihat dari kebutuhan teknis/operasi perusahaan yang telah terpenuhi.

5. Berdasarkan aspek finansial pendirian anak perusahaan training provider ini layak dilaksanakan. Dilihat dari hasil beberapa metode perhitungan finansial sebagai berikut :
a. Nilai Payback Periodnya 1,2 bulan $<5$ tahun.
b. Nilai Net Present Valuenya \$ 42.204.093,66>0.
c. Nilai Profitabilty Indexnya 30,54286574 > 1.
d. Nilai Return Of Invesment 1.114,037507\%.

\section{Daftar Pustaka}

[1] Abdullah, M. R. (2017). Studi Kelayakan Bisnis..

[2] Amin, A. M., Baga, L. M., \& Tinaprilla, N. (2018). Strategi Perencanaan Model Bisnis Perusahaan Jasa Konsultan Arsitektur dan Jasa Kontraktor PT Architectaria Media Cipta.MANAJEMEN IKM: Jurnal Manajemen Pengembangan Industri Kecil Menengah, 13(1), 55-65.

[3] Ardiana, A. (2014). Innovation Business Canvas Model Pada Produk Dholpine Yang Ramah Lingkungan (Doctoral dissertation, Universitas Muhammadiyah Surakarta).

[4] Hardjana, A. M. (2001). Training SDM yang efektif. Kanisius.

[5] Kurniasari, R., \& Kartikasari, D. (2018). Penerapan Model Bisnis Kanvas Terhadap Bisnis Jasa Angkut Penumpang Pada PT Internasional Golden Shipping. Journal of Applied Managerial Accounting, 2(1), 6-14.

[6] Nirmala, P. A. (2018). Analisis Strategi Pengembangan Usaha Pirez Laundry Samarinda. Universitas Mulawarman. Samarinda.

[7] Osterwalder, A., \& Pigneur, Y. (2010). Business model generation: a handbook for visionaries, game changers, and challengers. John Wiley \& Sons.

[8] Rainaldo, M., Wibawa, B. M., \& Rahmawati, Y. (2017). Analisis Business Model Canvas Pada Operator Jasa Online Ride-Sharing (Studi Kasus Uber di Indonesia). Jurnal Sains dan Seni ITS, 6(2), D232-D236. 